\title{
A Bayesian Network Approach for Coastal Risk Analysis and Decision Making
}

\author{
W.S. Jäger ${ }^{\mathrm{a}, *}$, E.K. Christie ${ }^{\mathrm{d}}$, A.M. Hanea ${ }^{\mathrm{c}}$, C. den Heijer ${ }^{\mathrm{a}, \mathrm{b}}$, T. Spencer ${ }^{\mathrm{d}}$ \\ ${ }^{a}$ Delft University of Technology, Faculty of Civil Engineering and Geosciences, Department \\ of Hydraulic Engineering, Delft, The Netherlands \\ ${ }^{b}$ Deltares, Department of Marine and Coastal Information Systems, Delft, The Netherlands \\ ${ }^{c}$ The University of Melbourne, Centre of Excellence for Biosecurity Risk Analysis, \\ Melbourne, Australia \\ ${ }^{d}$ University of Cambridge, Department of Geography, Cambridge, United Kingdom
}

\begin{abstract}
Emergency management and long-term planning in coastal areas depend on detailed assessments (meter scale) of flood and erosion risks. Typically, models of the risk chain are fragmented into smaller parts, because the physical processes involved are very complex and consequences can be diverse. We developed a Bayesian network (BN) approach to integrate the separate models. An important contribution is the learning algorithm for the BN. As input data, we used hindcast and synthetic extreme event scenarios, information on land use and vulnerability relationships (e.g., depth-damage curves). As part of the RISC-KIT (Resilience-Increasing Strategies for Coasts toolKIT) project, we successfully tested the approach and algorithm in a range of morphological settings. We also showed that it is possible to include hazards from different origins, such as marine and riverine sources. In this article, we describe the application to the town of Wells-next-the-Sea, Norfolk, UK, which is vulnerable to storm surges. For any storm input scenario, the BN estimated the percentage of affected receptors in different zones of the site by predicting their hazards and damages. As receptor types, we considered people, residential and commercial properties, and a saltmarsh ecosystem. Additionally, the BN displays the outcome of different disaster risk reduction (DRR) measures. Because the model integrates the entire risk chain with DRR measures and predicts in real-time, it is useful for decision support in risk management of coastal areas.
\end{abstract}

Keywords: Natural hazards, disaster risk reduction, southern North Sea, source-pathway-receptor concept

\footnotetext{
* Corresponding author

Email address: w.s.jager@tudelft.nl (W.S. Jäger)
} 


\section{Introduction}

About $10 \%$ of the world's population lives in low-lying coastal areas, where they are vulnerable to extreme events generated by the combined impact of waves, surges and tides [1. For example, if the sea surface elevation is higher 5 than a coastal defense, water overtops [2] or overflows [3] the structure and floods the hinterland. Moreover, engineered flood defenses may fail catastrophically under extreme loading conditions [4, 5. Similarly, beach and dune erosion at sandy coasts can threaten structures close to the shoreline or result in breaches and inundation 6, 7]. As a consequence, coastal communities may suffer from material damages, economic, political and social disruption, health issues, or damaged ecosystems 8 .

Under extreme circumstances, coastal storms can lead to societal disasters. For example, around 1100 lives were lost when Hurricane Katrina made landfall in New Orleans in 2005 9. More recently, 47 people died in La Faute-sur-Mer,

15 France, during storm Xynthia in 2010 [10. These events emphasize a continuing need for effective coastal risk management; this is all the more important as risks are projected to increase globally, due to growing populations and assets, accelerated sea level rise and potential increases in storminess (both tropical and extra-tropical) [11.

20 Coastal risk management essentially includes two types of activities: taking prompt actions in the face of an impending storm and long-term planning. Accordingly, we distinguish between a hot phase and a cold phase. In the hot phase, emergency managers depend on real-time and reliable predictions of the expected conditions in the coastal zone, as they attempt to select mitigation

25 measures and allocate limited resources minimizing the total sum of negative impacts. In the cold phase, multiple actors, including politicians, local stakeholders and scientists, cooperate to determine sensible strategies for reducing risks in an uncertain future [12. To evaluate these strategies against historical and conceivable future storms, they turn to impact assessments of the various scenarios.

Cutting across numerous disciplines, including oceanography, coastal science and engineering, statistics, economics, and social and political science, coastal risk assessment is highly challenging. Each field has complex models which target individual elements of the risk process. For example, multivariate 35 probability models estimate the return periods of extreme storms [13, 14, while numerical models, based on, for instance, hydro- and morphodynamic processes, determine the respective natural responses of the coast and extent of flooding [15, 16, 17, 18. Finally, behavioral or statistical models estimate the diverse and complex consequences onshore [19, 20, 9, 21]. However, risk management 40 requires a framework that integrates the individual elements of the risk process. 22 .

Two primary issues arise when attempting to incorporate offshore sea conditions with their expected onshore hazards and impacts into a single model for operational use. Numerical models, being computationally expensive, often 45 have a long run time, while instant assessments are needed for any conceivable 
hazard scenario during both the hot and cold management phases. On the other hand, the spatial and temporal scales of numerical and impact models differ from one another and need to be integrated. Whereas numerical models have grids whose sizes depend on the physical properties of the area under consideration, impact models usually operate on the level of individual receptors.

In the Netherlands, Jonkman et al. [8] assessed the flood hazard and corresponding damages to the built environment, loss of life, as well as indirect economic impacts (e.g., the interruption of production flows) for one hypothetical extreme event. The fundamental element of this approach is a spatial database 55 through which they connect output and input of the individual models according to a common spatial attribute. While addressing the challenges of different scales, the approach was limited to a single storm scenario. In principle, other storms could be assessed similarly, but the computational time is determined by the underlying numerical models. For this reason, the approach may not be suitable to predict flood hazards and damages for an impending storm or to compare multiple hypothetical storm scenarios during round-table discussions of stakeholders.

In contrast, Poelhekke et al. 23] integrated a wide range of simulated storm scenarios in a discrete Bayesian network (BN) and assessed related onshore 65 hazards in Praia de Faro, Portugal. A BN is a graphical model that describes system relations in probabilistic terms and can give instantaneous predictions. Nevertheless, Poelhekke's approach did not estimate impacts nor does it provide insight into the effectiveness of risk reduction measures. As far as we know, no model has been proposed which renders instant assessments for various possible

70 storm scenarios and captures the entire risk chain from sea conditions to onshore impacts.

In this article, we design a decision support system (DSS) for the hot and cold phases of coastal risk management as a $\mathrm{BN}$. We build on the widely recognized source-pathway-receptor (SPR) concept and attempt to extend and generalize 75 the work of Poelhekke et al. 23]. The DSS is part of a suite of tools, developed in the RISC-KIT project, whose purpose is to help effective disaster risk reduction (DRR) management at coasts 24. For different extreme event scenarios, the BN predicts percentages of affected receptors in terms of the hazards experienced and their impacts in real-time. Moreover, the BN can evaluate the effects of so potential DRR measures. Although our focus is on marine storms, which are the primary threat to coastline stability, the approach is broader. It is also possible to include, or even solely concentrate on, other types of natural disasters, such as extreme river discharges or exceptional rainfall events in this model.

The remainder of the paper is organized as follows. In Section 2, we introduce 85 the methodological background. We explain the SPR-concept and provide the basic theory of discrete BNs. In Section 3, we describe the design of the DSS, followed by examples from the case study site of Wells-next-the-Sea, Norfolk, UK, in Section 4. Finally, in Section 5, we discuss limitations and potential of the approach and, in Section 6, we present our conclusions. 


\section{Methodological Background}

In this section we provide an overview of models for the different elements in the risk chain, following the logic of the source-pathway-receptor concept, as well as an approach to quantitatively assess the effect of DRR measures. After that we describe the method we use to integrate the various models and DRR measures: BNs.

\subsection{The Source-Pathway-Receptor concept}

The source-pathway-receptor (SPR) concept is a high-level framework to evaluate risks. It was first used to describe the possible movements of a pollutant from its source to a receptor 25] and is now well established in coastal risk management [26, 27, 28, 29.

In its basic form, the framework characterizes a causal chain of processes and events in terms of sources, pathways and receptors (Figure 11). When considering coastal storms, the chain reaches from offshore to onshore. The source is the offshore marine environment. Typical source variables, or boundary con105 ditions, are peak water level, maximum wave height and peak period, and storm duration. The storm threat can affect onshore areas through pathways. They are the interaction of water levels and waves with coastal landforms and ecosystems, coastal infrastructure and low-lying coastal hinterlands. Finally, receptors are the entities at risk, such as people, built environments or ecosystems.

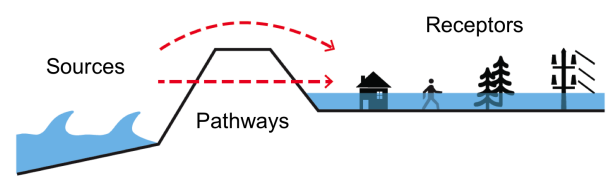

Figure 1: Illustration of the source-pathway-receptor (SPR) concept for coastal storms

Sometimes, the framework explicitly includes consequences $(\mathrm{C})$ as a fourth term. Any receptor can experience them, if affected by a hazard. Gouldby and Samuels [30] have defined a hazard as the triple: source, pathway and receptor. However, we consider a hazard to be a local condition directly affecting the receptors. Examples are flood depth, flow velocity and erosion, which can, for instance, cause structural damage or injuries.

Coastal risk assessments often follow this concept. The general idea is to generate a set of representative extreme event scenarios, model the pathways, and estimate the resultant impact [e.g., 31. More specifically, detailed and specific models are applied to various individual processes in the SPRC chain 120 and then linked together. However, to the best of our knowledge, a single model that captures the entire chain does not exist yet. 


\subsubsection{Source Models}

A set of scenarios that are representative for the storm climate at a given site can be derived from a statistical analysis. Often, storms are characterized by the values of hydraulic variables in deep water at the peak of the storm along with its duration. In the past decade, copula-based models have become increasingly popular to estimate dependencies between (some) such variables [e.g., 13, 32, 33, 14. Copula models are a specific type of probability distribution that characterizes the dependence structure between random variables

130 irrespective of their marginal behavior. The temporal evolution of the variables, which is typically required as input for pathway models, is often idealized as a so-called equivalent triangle 34. Nonetheless, a couple of studies model times series explicitly [35, 36].

\subsubsection{Pathway Models}

The response of coasts to storms and the extent of flooding can be assessed with computational models, which numerically solve the physical equations that govern the motion of water and sediment in the nearshore and the hinterland.

A number of different models [e.g., 15, 16, 17, 18, varying in their numerical solutions, spatial dimensions and the range of physical processes included, have been successfully applied to the problem of hazard modeling in different coastal settings [e.g., 37, 38, 39]. The models are driven by time series of meteorological or hydraulic variables at the offshore boundary of their domain. Their output contains time series of hydraulic or morphological variables, which are potential hazards at the shore and in the hinterland, on a structured or unstructured 145 numerical grid.

\subsubsection{Consequence Models for Receptors}

Diverse and complex consequences can arise from flooding or erosion. Separate approaches can estimate economic, political, social, cultural, environmental or health-related consequences. In general, these approaches operate on the receptor level. Most commonly, they are functions, often referred to as vulnerability relationships, which map one or multiple hazards to consequences for a specific type of receptor. Literature reviews on vulnerability relationships exist, for instance, for economic damage [21, health impacts [19, 20], and the loss of life [40] due to flooding.

\subsection{Disaster Risk Reduction Measures in Models}

According to the terminology of the United Nations Office for Disaster Risk Reduction, DRR measures reduce the exposure to hazards or lessen the vulnerability of receptors [1]. For modeling, a similar categorization into three types is useful, as we explain below. Exposure-reducing measures move receptors out 160 of high risk areas, for instance, by temporarily evacuating people or permanently relocating residential areas. Pathway-obstructing measures change the bathymetry and hence its interactions with waves and water levels. Examples are beach or dune nourishment, revetments and floodwalls. The third type are 
vulnerability reducing measures, which include for instance flood protection for individual receptors. Also raising the awareness of potential flooding and flood impacts amongst inhabitants belongs to this category.

Modeling the effect of DRR measures belonging to one of the first two types is straightforward. For exposure-reducing measures, receptors are excluded from the model or different types of land-use can be assumed for high risk areas. For 170 pathway-obstructing measures, the pathway models can be modified and the effect simulated. Modeling vulnerability-reducing measures is more intricate. In principle, their effect is assessed by modifying consequence models [e.g., 42]. Some such measures such as early warning or awareness raising, depend on effective uptake or operation by people. To accommodate this, Cumiskey et al.

175 43. developed a methodology to quantify and aggregate factors that influence uptake and operation.

\subsection{Bayesian Networks}

In this section we explain the basic theory of BNs, as we will use them to integrate the individual approaches into a homogeneous framework. BNs represent a joint probability distribution over a set of random variables. If one or more variables are observed, the $\mathrm{BN}$ evaluates the influence of this new evidence on the distributions of all other variables. If the model is "small enough", it can predict changes in distributions instantly and can be interpreted intuitively. For this reason, BNs have been used as early warning systems for natural haz185 ards [23, 44, 45] and as input for negotiations and discussions between experts, managers, stakeholders and citizens [46, 47, 48. In coastal settings, such models have been shown to successfully predict erosion and shoreline retreat 49, 50, 51. BNs have also proved to be valuable for estimating damages to residential buildings after hurricanes 52 and to evaluate the risk to nuclear facilities from coastal hazards [53].

A discret $f^{1} \mathrm{BN}$ represents the joint probability mass function of a set of random variables $\mathbf{X}=\left\{X_{1}, \ldots, X_{n}\right\}$ as a directed acyclic graph [54, 55]. Each variable constitutes a node in the graph. The nodes are connected by arcs which indicate potential dependence between variables. The direction of an arc, from so-called parent to child, signifies the direction of influence. The arcs must not form a cycle; no path $X_{i} \rightarrow \cdots \rightarrow X_{i}$ may exist for any $i=1, \ldots, n$. Figure 2 illustrates such a graph structure.

The semantics of the graph stipulate that each $X_{i}$ is conditionally independent of all predecessors given its parents. Therefore, a joint probability distribution $P\left(X_{1}, \ldots, X_{n}\right)$ can be economically factorized through the chain rule:

$$
P\left(X_{1}, \ldots, X_{n}\right)=\prod_{i=1}^{n} P\left(X_{i} \mid p a\left(X_{i}\right)\right),
$$

\footnotetext{
${ }^{1}$ We do not consider continuous BNs in this article.
} 


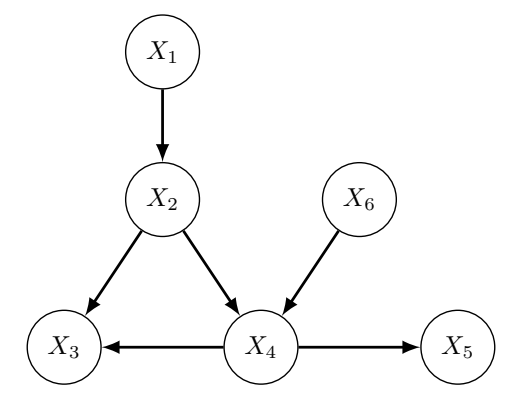

Figure 2: Example of a directed acyclic graph on six variables

where $p a\left(X_{i}\right)$ denotes the set of parent nodes of $X_{i}$. The factors $P\left(X_{i} \mid p a\left(X_{i}\right)\right)$ on the right hand side of the equation are stored as conditional probability tables (CPTs), or in case of no parents as probability tables (PTs), and associated with each node $X_{i}$. Together, the graph semantics and all CPTs uniquely specify the joint probability mass function of $\mathbf{X}$.

A BN's computing algorithm uses Bayes' theorem. Lauritzen and Spiegelhalter 56] developed exact algorithms for high dimensions, which are implemented in most BN software. In two dimensions the theorem is given by

$$
P\left(X_{1} \mid X_{2}\right)=\frac{P\left(X_{2} \mid X_{1}\right) P\left(X_{1}\right)}{P\left(X_{2}\right)} .
$$

$P\left(X_{2} \mid X_{1}\right)$ is the CPT of node $X_{2} . P\left(X_{1} \mid X_{2}\right)$, which is computed, is called the posterior distribution, and can be interpreted as the updated distribution of $X_{1}$ taking into account new evidence on $X_{2}$.

The CPTs and PTs can be learned from data, specified based on experts' estimates or derived from equations. In the next section, we describe the general structure of the DSS and explain how we quantified the CPTs and PTs.

\section{Design of the Decision Support System}

$$
\text { repronto }
$$
variables of the same category. As a consequence, all boundary conditions, receptor types and DRR measures are mutually independent, while hazards and consequences are conditionally independent of each other given their parents. 220 Admittedly, this assumption may appear unnatural for boundary conditions and DRR measures. We reflect on this issue when describing those categories in Sections 3.3 and 3.4 .1 . 


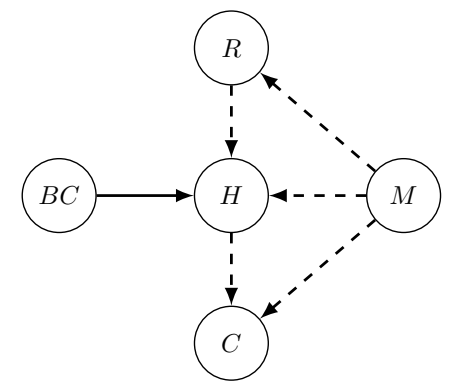

Figure 3: High-level framework of the DSS for coastal risk management illustrating the influences between boundary conditions $(B C)$, receptors $(R)$, hazards $(H)$, consequences $(C)$, and risk reduction measures $(M)$. The solid arc indicates that all variables of the parent category influence all variables of the child category. If this is not the case, the arc is dashed.

All boundary conditions influence all hazards, which is indicated by the solid arc in Figure 3. In contrast, each type of receptor (e.g., people, buildings, in-

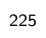
node (representing the locations of receptors on the site) as well as $H$ nodes (representing the hazards given the receptors' locations) and $C$ nodes (representing the consequences given (some of) the receptors' hazards). The dashed arcs in Figure 3 represent the fact that the sub-modules are not directly interare boundary conditions and, possibly, DRR measures.

While the high-level representation is generic, the $\mathrm{BN}$ is tailored to case study sites through the choice of variables and the supplied training data, based on the characteristics of the site under investigation. Owing to the generic structure, the process of constructing the BN can be automated and, if desired, integrated with open shell systems that manage forecasting processes, such as Delft-FEWS [57. We developed specific file formats in which variable definitions and training data need to be provided, as well as a $\mathrm{C}++$ program to read them and create a BN. The source code is open and available at https://github.com/openearth/coastal-dss. An executable for Windows and documentation is also provided. The core of our program builds on SMILE, which is a reasoning engine for graphical models. It is available free of charge for academic research and teaching use from BayesFusion, LLC, http://www.bayesfusion.com/.

\subsection{Training Data}

In essence, the training data comprises a set of storm simulations, cadastral information on the case study site, and vulnerability relationships (cf. section 2.1.3. Additional data may be required to include risk reduction measures, as described in Section 3.3 .

The set of simulations should reflect the storm climate of the site. Each storm 250 is defined by an offshore time series of waves and water levels, which is typically assumed to be uniform along the offshore boundary, and the simulation shows its propagation into the hinterland. For simplicity, we use statistics of the offshore 
time series, such as maxima and averages, to characterize the storm. In our decision support framework, these statistics are the variables of the $B C$ category. Ideally, the storm scenarios are derived from a multivariate statistical analysis of measured wave and water level time series [e.g.,23, 35] and can be a combination of historical and synthetic events. However, if adequate data or analysis tools are not available, the scenarios can also be derived from expert opinion (e.g., with the classical model for structured expert judgment and extensions thereof [58, 59.

As the $B C$ category is related to input of the simulations, the $H$ category is related to output. Statistics of the gridded time series of hydraulic or morphological variables in the hinterland constitute the $H$ variables. Finally, the data for the $R$ variables stem from the cadastral information and the data for the $C$ variables are estimated from the $H$ variables using vulnerability relationships. In each category, the CPTs or PTs of the variables are learned differently, as will be explained in the following section.

\subsection{Including DRR Measures}

DRR measures do not have PTs. They are implemented as decision nodes $2^{2}$ and not as random nodes, because their states represent the actions of decision makers. For the same reason, measures are not interconnected with arcs. To avoid situations in which incompatible measures are simultaneously selected, they can be treated as different states of the same variable. When there are no conflicts, the variables typically have two states ("in place" and "not in place").

The three types of measures described in Section 2.2 can be incorporated into the BN. To demonstrate the outcome from exposure-reducing measures, we conceptually move receptors to a safe zone. To show the effect the pathway obstructing measures, we simulate different storm scenarios with the original and the adapted bathymetry. Finally, we modify vulnerability relationships and, if applicable, include a measure effectiveness factor to account for effective uptake and operation of vulnerability-reducing measures.

\subsection{Quantification of (Conditional) Probability Tables}

\subsubsection{Boundary Conditions}

The BN learns the PTs of BC nodes from storm simulations. The PT entries are set to the relative frequencies of observed values in all simulations. Although there may be notable dependencies between hydraulic boundary conditions (cf. Section 2.1.1p, these are not modeled with the current version of the program; boundary conditions do not have parents. We reflect on the implications of this assumption in the discussion (Section 5).

\footnotetext{
${ }^{2}$ While we include decision nodes, our model is not an influence diagram, because it does not solve for an optimal decision in terms of a maximum expected utility.
} 


\subsubsection{Receptors}

Each receptor type, such as building, people or infrastructure, is associated with a node that characterizes the location of a randomly selected object or individual. To this end, the case study site is divided into zones (including the external safe area, if applicable). A division is subjective and depends on features of the site; natural topological or political boundaries can be used. The zones are identical for all receptor types.

Figure 4 shows an illustration site with 26 houses across two zones: the beachfront and inland. We denote the node for the receptor type house as $X_{\text {house }}$. To understand why we consider the location of an individual house as uncertain, imagine selecting one of them randomly, just like drawing a ball from an urn. The probability for a house to be within a given zone is proportional to the total number of houses in that zone. Because 10 houses are located at the beachfront and 16 inland at the illustration site, $P\left(X_{\text {house }}=\right.$ beachfront $)=5 / 13$ and $P\left(X_{\text {house }}=\right.$ inland $)=8 / 13$. The same entries of the PT can be thought of as a spatial distribution of the houses in terms of the zones.

Note that the number of receptors in a zone could change for different combinations of exposure influencing DRR measures. In that case $X_{\text {house }}$ would have a CPT and not a PT, because DRR measure variables would be parent nodes.

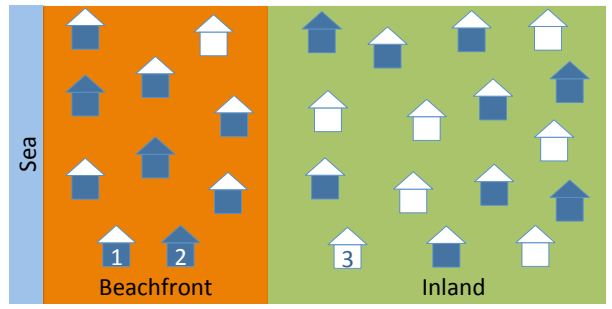

Figure 4: Illustration site with 26 houses distributed across 2 zones. The color of a house indicates its degree of flooding: none is white, medium is white-blue, and high is blue.

\subsubsection{Hazards}

The BN learns the CPTs of hazards from storm simulations as well, however in a different manner than the PTs of boundary conditions. Now, the CPT entries represent, for each degree of hazard severity, an estimate for the proportion of affected objects or individuals. They can also be interpreted as the probability of degree of hazard severity for a randomly selected receptor. Of course the proportions vary depending on the zone, the boundary conditions and the DRR measures in place.

We illustrate the learning with an example and refer the reader to Appendix A for the precise algorithm. Consider again the illustration in Figure 4 We call the combination of boundary conditions and DRR measures a scenario. The hazard variable, flood depth, has three states: none, medium and high. The flood depth at each house is indicated by its color: white, white-blue or 
blue. In the beachfront zone, $3 / 10$ houses experience a high flood depth, 6/10 a medium depth, and $1 / 10$ none. These three numbers are the CPT entries given

325 the scenario and for the zone beachfront. Similarly, the entries are 3/16, 6/16 and $7 / 16$, for the zone inland under the same scenario.

Because the local features of a site influence the flood flow, the degree to which a receptor is affected depends on its exact location. Without resolving to the spatial scale of individual receptors, this is reflected by the above fractions.

330 As other types of receptors have a different spatial configuration (and total number), their fractions are different. Therefore, we model hazards separately for each receptor type.

Finally, due to the discretization, it is not possible to distinguish storms whose boundary conditions fall into the same pre-defined states. In such cases, we average the observed fractions.

\subsubsection{Consequences}

Consequences have truth tables, which are a special case of CPT. In a truth table each combination of parent states corresponds to a single child state with probability 1. Hence, the relationship of consequences to their parents is deterministic. In this $\mathrm{BN}$, we use vulnerability relationships, which are commonly used in the field (cf. section 2.1.3), to compute consequences as a function of hazards and DRR measures.

\section{Application to North Norfolk, UK}

\subsection{Case Study Site}

The North Norfolk coast is a north-facing coastline, characterized by both gravel and sand barriers, with an extensive (>2000ha) saltmarsh area behind barrier islands, spits and areas of low gradient sand flats on open coasts. In this area the natural environment is a major source of revenue for the local economy via its contribution to nature-based tourism and recreational uses. Analysis of

350 coastal hazards along this stretch of coast has highlighted Wells-next-the-Sea as a risk hot spot [60].

Wells is a small coastal town (population 2165, 2011 Census). It is the largest urban center on the North Norfolk coast. The main industry of Wells is tourism, but there is also a small fishing and a wind farm servicing industry.

355 The town has a long history of flooding due to storm surges. As such, the coastal defenses have been improved over time. The embankment forming the western side of the Wells Harbour Channel breached in the catastrophic storm of 1953 [61] and again in the storm surge of 1978 [62, leading to considerable areas being flooded on the western side of the town. Following the storm surge 360 of 1978, this embankment was re-built to a much higher specification and, as a consequence, withstood the December 2013 surge with minimal damage [63]. In addition, the raising of the flood wall to the south of this embankment and the construction of a movable barrier between this defense and the building line at the back of the Wells Quay has reduced the risk of flooding to the low-lying 

have also implemented property level protection measures.

\subsection{BN Specification}

Following the general structure introduced in Figure 3 , the BN for Wells has boundary conditions, DRR measures, receptors, hazards and consequences. 370 Figure 5 shows the graph of the BN. The boundary conditions are maximum water level and maximum wave height. There are four receptor types, each with its own hazards and consequences. For residential and commercial properties we include flood depth and absolute monetary damage. For people we assess the maximum depth-velocity product experienced and the risk to life. For the

375 saltmarsh, we include flood depths and wave height, and damage in terms of an ecosystem vulnerability indicator (cf. Table 2). Finally, there are two pathway obstructing measures (extending the sea wall and increasing its height) and a vulnerability reducing measure (raising awareness through display boards).

The BN is trained with 85 storm scenarios representing the range of potential extreme event conditions, which are generated from coastal scale modeling. They include historical storms ( 8 scenarios), climate change (18 scenarios) and synthetic events (59 scenarios).

\subsubsection{Boundary Conditions}

We defined the extreme events at Wells in terms of the peak water level and maximum significant wave height. We calculated the boundary conditions from a model train (Figure 6), which transforms coarse external model conditions to detailed model results at the BN boundary condition location (Wells harbour channel entrance, $52.993 \mathrm{~N} 0.853 \mathrm{E}$ ) and generates the input conditions for the model train to calculate the subsequent flooding.

${ }_{390}$ The model train uses predicted hindcast data at 12 locations from the CS3 (before 2007) and CS3X (post 2007) tidal surge model run by the National Oceanography Centre, UK (NOC). The model predicts hourly tide and surge residual data with a resolution of approximately $12 \mathrm{~km}$ which are used to drive a 2D TELEMAC model [16]. The TELEMAC model extends $50 \mathrm{~km}$ offshore from the case study site, over an area of $4750 \mathrm{~km}^{2}$. The unstructured grid consists of 10,704 elements with 5759 nodes. The largest elements have a resolution of $12 \mathrm{~km}$ but the grid resolution becomes finer towards the coast with the smallest resolutions in the Wells Harbour channel of approximately $15 \mathrm{~m}$.

The wave conditions are generated at the entrance to the harbour channel by

${ }_{400} 2$ nested SWAN models 64. The nested SWAN models are driven by 2D spectra from the UK Met Office Wavewatch III (WWIII) North Atlantic European model with a resolution of approximately $12 \mathrm{~km}$. The Met Office model has a spectral resolution of 25 frequency bins and 24 directional bins. It is forced by a $10 \mathrm{~m}$ wind field from the Met Office Numerical Weather Prediction models 405 and the Global Wave Model. The wind characteristics are obtained from the $10 \mathrm{~m}$ wind field from the Met Office Numerical Weather Prediction model. The water level and flow velocities are obtained from the TELEMAC model and 


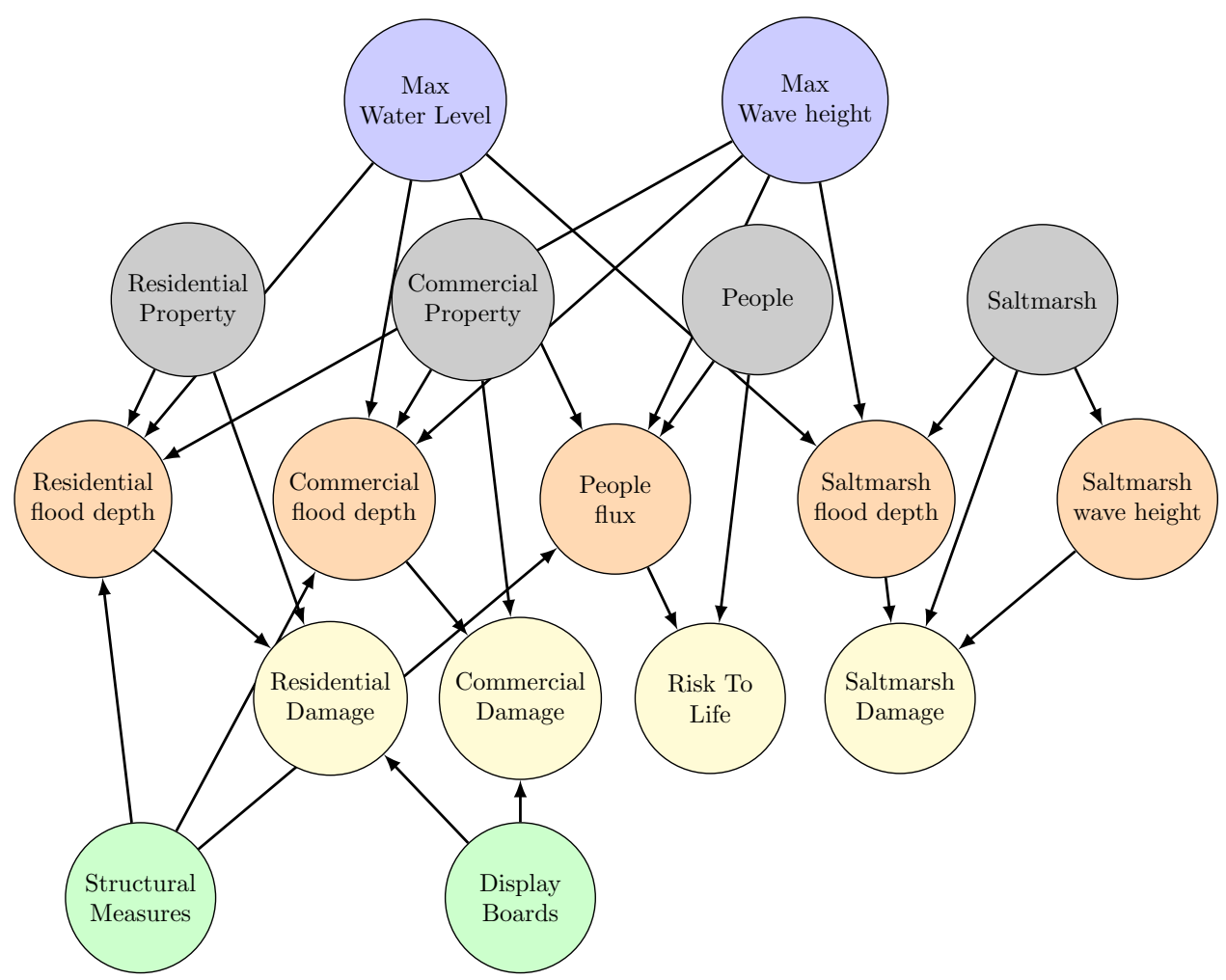

Figure 5: Framework of the Bayesian Network for Wells-next-the-Sea

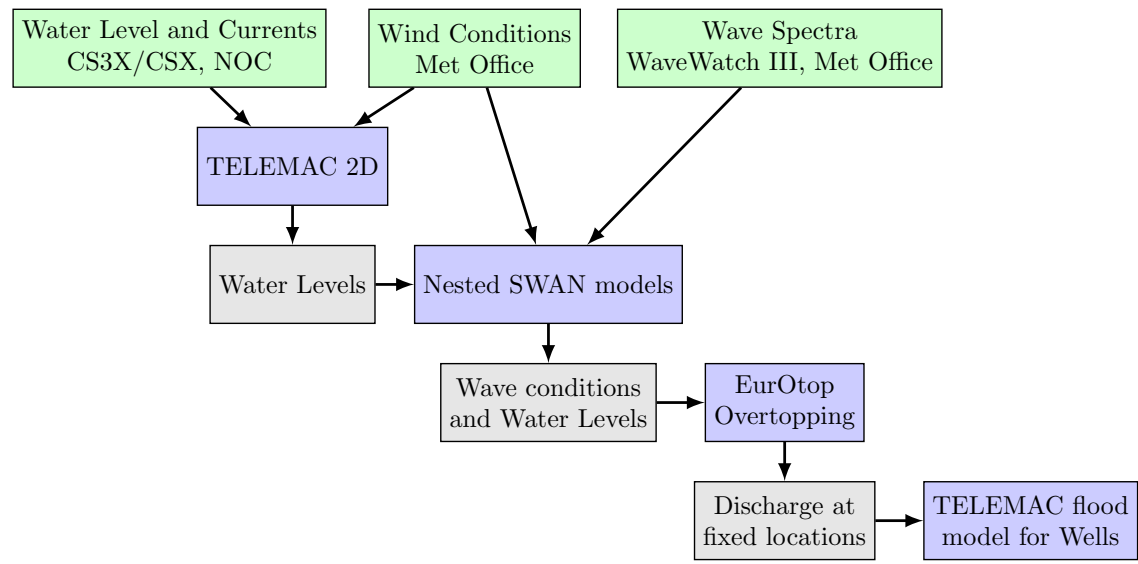

Figure 6: Framework of the Model train to assess the flood hazard in Wells-next-the-Sea, North Norfolk, UK.

interpolated onto the the nested SWAN model grids. The largest of those grids 
covers an area of $90 \times 60 \mathrm{~km}$ with a resolution of $5 \mathrm{~km}$, the smaller grid covers an area of $32 \times 13 \mathrm{~km}$ with a resolution of $500 \mathrm{~m}$. Wave growth from wind, whitecapping, quadruplets, breaking waves, diffraction, triad interactions and setup are included in the models using the present default settings (SWAN version 41.01 [65]).

The historic storm events were generated by external model hindcast storms

415 selected where boundary conditions were available from external models. In total eight historic storm surge events were selected: 20-21 February 1993, 10 January 1995, 19-20 January 1996, 14 December 2003, 31 October-3 November 2006, 17-20 March 2007, 7-10 November 2007, and 4-7 December 2013. Synthetic storm events were generated to produce a fuller range of potential storms ${ }_{20}$ based on historic surge and wave conditions. The synthetic storms were generated using a typical spring tide, with length of 55 hours, with the addition of a storm surge residual from one of eight historic storm surges. The peak storm surge residual coincided with the peak tidal water level. To create a greater range of synthetic storms the spring tide or storm surge residuals were multi-

425 plied by a factor $(0.7-1.3)$. Analysis of the historic surge events found no clear dependencies between the surge and wave characteristics. At this location it is clear that it is the high water levels, usually caused by the coincidence of a surge event with high water on a high spring tide, which generates the flooding. In order to create representative wave conditions which are likely to occur with

${ }_{430}$ a surge, the synthetic storm wave and wind conditions were taken from the historic storm events. The synthetic storms cover a range of conditions up to a return period of 400 years, based on peak water level. Only those synthetic storms which had an impact are included in the BN.

Climate change scenarios were generated by modifying the boundary conditions from the historical storm event hindcast model to include a sea level rise prediction. The climate change scenario sea level and surge data were based on the IPCC (2013) RCP8.5 (Representative Concentration Pathway) projections for 2060. The future extreme storm surge levels (SSL) along the European coasts have been predicted by Vousdoukas et al. 66, using a DELFT3D-Flow 440 model forced by an 8 member climate model ensemble. The authors predict the RCP8.5 2060 relative sea level rise (RSLR) at the case study site $(52.98 \mathrm{~N}$ $1.228 \mathrm{E}$ ) to be $+39 \mathrm{~cm}$ and the predicted change in surge height in 2060 for a 20 year return period is $-4 \mathrm{~cm}$, giving an overall climate effect of $+35 \mathrm{~cm}$.

\subsubsection{Receptors}

${ }_{445}$ We divided the case study site into 6 zones, based on topographic features and key current flood prevention measures, such as the flood wall and movable flood barrier. The receptor types are residential property, commercial property, people and saltmarsh. Their locations are shown in Figure 7. We did not include caravans as receptors themselves, but we did include the people living

450 inside the caravans in the analysis. We considered people to be inside their homes/caravans at the time of the flooding impact. The model assumed a ratio of $3: 1$ for the number of people in houses to caravans. 


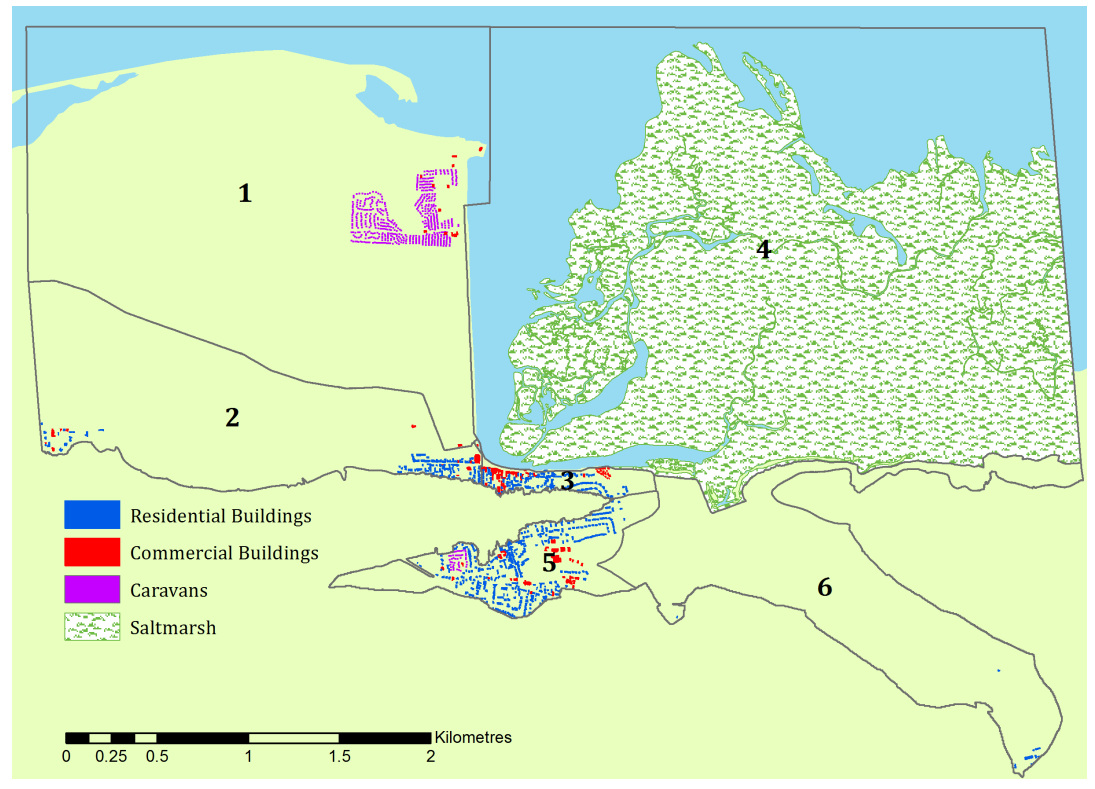

Figure 7: Defined zones in Wells-next-the-Sea and receptor locations

\subsubsection{Hazards}

We obtained detailed hazard values (inundation depth, flow velocity, wave height) by modeling the flood inundation in the study area and by mapping the receptor locations at their nearest grid point.

A small SWAN model $(4 \mathrm{x} 4 \mathrm{~km}$ with a resolution of $15 \mathrm{~m})$ calculates the wave height within the harbor channel. It includes the wave energy dissipation due to the saltmarsh vegetation adjacent to the Wells Harbor (plant height $=0.11 \mathrm{~m}$, field data from Stiffkey, North Norfolk [67; plant diameter $=0.00125 \mathrm{~m}$ 68, plant density=1061 plants per $m^{2}$, field data at Tillingham, Essex [69]). From the SWAN model we obtained water level and wave conditions at 64 locations along the Wells Harbor Channel. We calculated overtopping rates at transects at these 64 locations using EurOtop [70] and used the resulting overtopping discharge to 465 drive a flood inundation model for the town. The inundation model covers an area of $7.5 \mathrm{~km}^{2}$, the whole of Wells-next-the-Sea and some of the surrounding countryside. The landward margin of the flood grid is defined by the $10 \mathrm{~m}$ Ordnance Datum Newlyn (ODN) contour. The majority of the grid has an approximately $12.5 \mathrm{~m}$ resolution. A finer resolution is needed to represent the current flood wall and DRR measures in the mesh; therefore a resolution of $0.5 \mathrm{~m}$ is used at the wall.

\subsubsection{Consequences}

We determined the impact of the flooding with vulnerability relationships. For residential properties, we estimated the potential absolute damage from the 

detached houses [71, the most common property type in Wells. The residential properties are divided into those with flood protection and those without protection. From a site and Google Street View survey only 17 of 960 houses below $10 \mathrm{~m}$ ODN were found to have any form of property level protection measures in up to date protection to the current standards. UK industry standards assume that resistance measures protect up to $0.6 \mathrm{~m}$ above the threshold of the house [71. The depth-damage curves were therefore modified for properties with flood protection, so that no damage occurred below $0.6 \mathrm{~m}$.

Commercial properties are also divided into those that have flood resistance measures and those that are unprotected (surveys found 10 properties with flood protection out of a total of 140 surveyed). Commercial properties within the case study site are typically small shops, restaurants, pubs, cafés and small warehouses. We assumed that the depth-damage curve data for retail adequately depth-damage curve data from Penning-Rowsell et al. [71 for retail properties with no cellar, a short duration flood and a mean area of $140.45 \mathrm{~m}^{2}$. We modified the curve following the same principle as for the residential properties with flood resistance measures.

495 As is common in the field, we calculated risk to life through the matrix developed by Priest et al. 72, which is based on the depth velocity product experienced and the vulnerability of the area (Table 1). Vulnerability of the area is based on the type of buildings and the construction methods at three levels: low vulnerability is applied to masonry, concrete and brick buildings; is applied to caravans, campsites, bungalows and poorly constructed buildings. We assumed that the area is largely medium vulnerability, as it is a typical residential area with mixed type of properties. An exception is zone 1 to the west of the earthen embankment at the edge of the Wells Channel, which we 505 defined as a high vulnerability area due to the large number of caravans (568 caravans in zone 1 ).

\begin{tabular}{|l|l|l|l|}
\hline & \multicolumn{3}{|c|}{ Nature of the Area } \\
\hline Depth Velocity product $m^{2} s^{-1}$ & Low Vulnerability & Medium Vulnerability & High vulnerability \\
\hline$<0.25$ & Low risk & Low risk & Low risk \\
$0.25-0.50$ & Low risk & Medium risk & Medium risk \\
$0.50-1.10$ & Medium risk & Medium risk & High risk \\
$1.10-7$ & Medium risk & High risk & Extreme risk \\
$>7$ & Extreme risk & Extreme risk & Extreme risk \\
\hline
\end{tabular}

Table 1: Risk to Life matrix [72, relating the depth-velocity product experienced during a flood event and the area vulnerability to the risk to life.

We estimated the damage to the saltmarsh by a ecosystem vulnerability indicator (Table 2), which relates damage to inundation depth and maximum wave height. We developed the saltmarsh vulnerability indicator from the work of Woodroffe [73] and Möller et al. 68. We assumed the saltmarsh at the case 
study site is an open coast marsh in a mesotidal area. For inclusion in the BN, the saltmarsh was divided into 372 individual units, based on the grid node locations of the TELEMAC model.

\begin{tabular}{|l|l|l|l|l|l|}
\hline & \multicolumn{5}{|c|}{ Wave Height $(\mathrm{m})$} \\
\hline Depth $(\mathrm{m})$ & $<0.3$ & $0.3-0.6$ & $0.6-1$ & $1-2$ & $>2$ \\
\hline 0 to 1 & 0 & 2 & 2 & 3 & 3 \\
1 to 2 & 0 & 1 & 2 & 2 & 3 \\
2 to 3 & 0 & 1 & 1 & 2 & 2 \\
3 to 4 & 0 & 0 & 1 & 1 & 2 \\
\hline
\end{tabular}

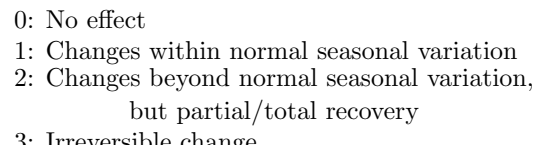

Table 2: Saltmarsh Ecosystem Vulnerability Indicator 74

\subsubsection{DRR Measures}

We tested two structural DRR measures: i) an extended flood wall and ii) increasing the height of the flood wall in combination with a movable barrier. We ran modified versions of the TELEMAC flood model to assess the change in the hazard experienced by the receptors. The extended flood wall lengthens the existing wall along the front of the harbor quay, protecting the properties in Area 3. The higher flood wall was chosen as water levels for the recent 2013 storm surge event almost reached the top of the existing defenses.

Additionally, we included iii) a vulnerability influencing DRR measure in the $\mathrm{BN}$. This takes the form of a series of display boards containing cartographic information on former shoreline positions to demonstrate coastal dynamics, and

525 images of flood markers along the coast to indicate elevations reached by historic storm surges. The aim of the display boards is to increase awareness of flood risk, with a hoped-for increase in property level protection.

To determine the effectiveness of the display boards we employed the method of Cumiskey et al. [43, which assumes that the effectiveness of DRR measure ${ }_{530}$ depends on three factors: uptake, operator and performance. The values for each of these factors are displayed in Table 3. Uptake is the percentage of the population who will adopt the measure. We calculated a value of $9 \%$ based on $50 \%$ of the population will see the display board, $30 \%$ of the population will want to take action as the threat and coping appraisal level are high and $60 \%$ of the population can afford the measures due to an above average income level. The operator factor is the percentage of the population that will operate the measure before a flood, calculated as 77.3\%. The Environment Agency [75] gives an operator value of $86.1 \%$, which was adjusted down as $24 \%$ of the population within the North Norfolk Area of Natural Beauty (AONB) are second home 540 owners. We assumed that a third of the second homes would have someone available to operate the flood protection (due to the probability of an event occurring at a weekend or holiday when second home owners are more likely to be in residence) (72.3\% operator value). With the use of the display boards it is expected that more of the population will be reminded to check they know how to operate the measures they have, giving a post DRR operation measure of $77.3 \%$. The performance factor is the percentage of the population who 
will operate the measure effectively. We calculated a value of $73 \%$ from the assumptions that $5 \%$ of equipment are lost or misplaced, $95 \%$ of the product are in good working order, $90 \%$ of the population receive a flood warning, and that there is a $90 \%$ chance that flood heights do not exceed flood protection level [76].

By combining the factors, we estimate an increase of property level protection with the display board DRR of $5.08 \%$. While it is possible to include the increase in protection as a measure effectiveness node, in this instance, we have directly modified the vulnerability relationships accordingly.

\begin{tabular}{|l|c|}
\hline Influencing Factors & Post DRR measure \\
\hline Uptake: \% of the population who will adopt the measure & $9 \%$ \\
\hline Operator: \% of the population that will operate the measure before a flood & $77.3 \%$ \\
\hline Perfomance: \% of the population who will operate the measure effectively & $73 \%$ \\
\hline
\end{tabular}

Table 3: Influencing factors for the effectiveness of the display board DRR measure

\subsection{Results}

We could predict hazards and impacts in Wells with the BN in real-time without the need for further detailed flood modeling, as the BN is trained with a range of potential storms. The BN also allowed the impact and cost-effectiveness of the DRR measures to be studied. The quantified model with its prior probabilities can be seen in Figure B.10 in Appendix B. In this section, we describe the $\mathrm{BN}$ results for a storm of $4.41 \mathrm{~m}$ water level and $2.17 \mathrm{~m}$ significant wave height. This storm was calculated as the 1 in 100 year return period storm based on the maximum water level only. For reference, the BN constraint on these bins is given in Figure B.11 in Appendix B.

The majority, 93.55\%, of residential properties had no flood inundation and therefore sustained no damages (Figure $8 \mathrm{a}$ ). Maximum inundation depths with an associated absolute damage of $£ 30,000-55,000$ reached $0.49 \%$ of the properties. The higher sea wall had little effect on the absolute damage distribution 570 (Figure 8k). The extended sea wall shifted the distribution of damage to lower values (Figure 8p). Display boards can be applied together with any of the structural measure options. Whilst the display boards had little influence on the largest damage bins, due to the property level protection only protecting up to $0.6 \mathrm{~m}$, the distribution of damage shifted to lower levels below $0.6 \mathrm{~m}$ (Figure $8 \mathrm{~d}, 8 \mathrm{e}, 8 \mathrm{f})$.

Commercial properties were at a greater risk in this scenario with $36.6 \%$ of commercial properties experiencing some flooding with no DRR measures in place (Figure 9a). 5.91\% of commercial properties were inundated by $1-3 \mathrm{~m}$ resulting in absolute damage of $£ 120,000$ to 200,000 . Again, the higher sea wall, 580 showed little damage reduction, suggesting that this is not a suitable measure for this storm scenario (Figure 9k). The extended sea wall reduced the number of commercial properties experiencing the highest levels of absolute damage (Figure 9b). The Display Board showed a shift to lower levels of damage for 
all the scenarios tested. However, they had no influence on the higher damage

levels due to the flood protection height limit (Figure 9d, 9p, 9f).
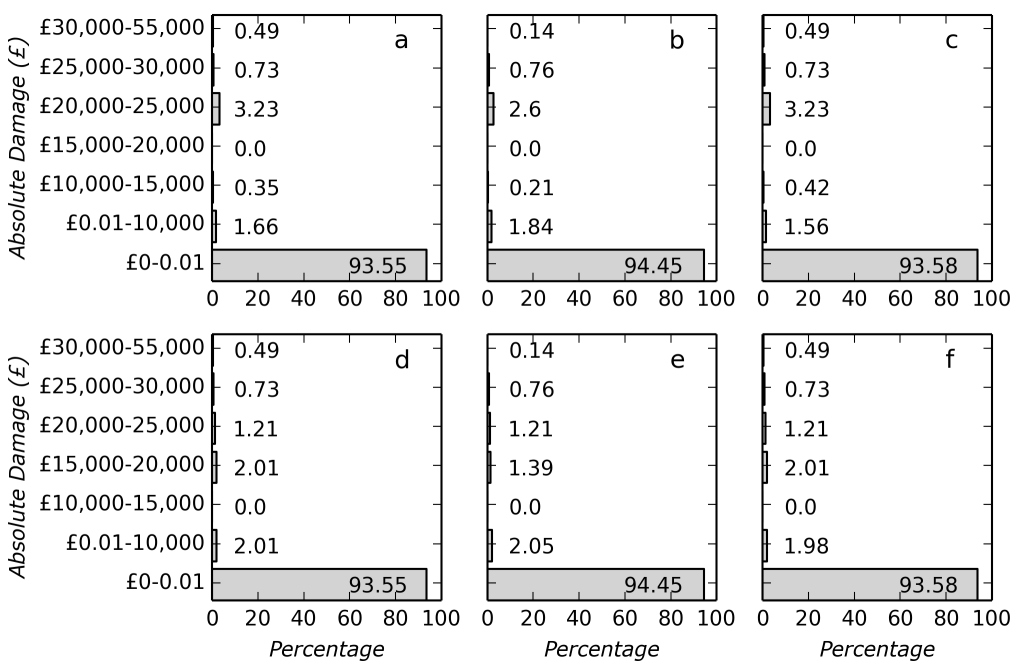

Figure 8: Absolute Residential Damage values for the 1 in 100 year return period storm with a) No DRR measures, b) Extended sea wall c) Higher sea wall d) Display Boards e) Display Boards and Extended sea wall and f) Display Boards and Higher sea wall
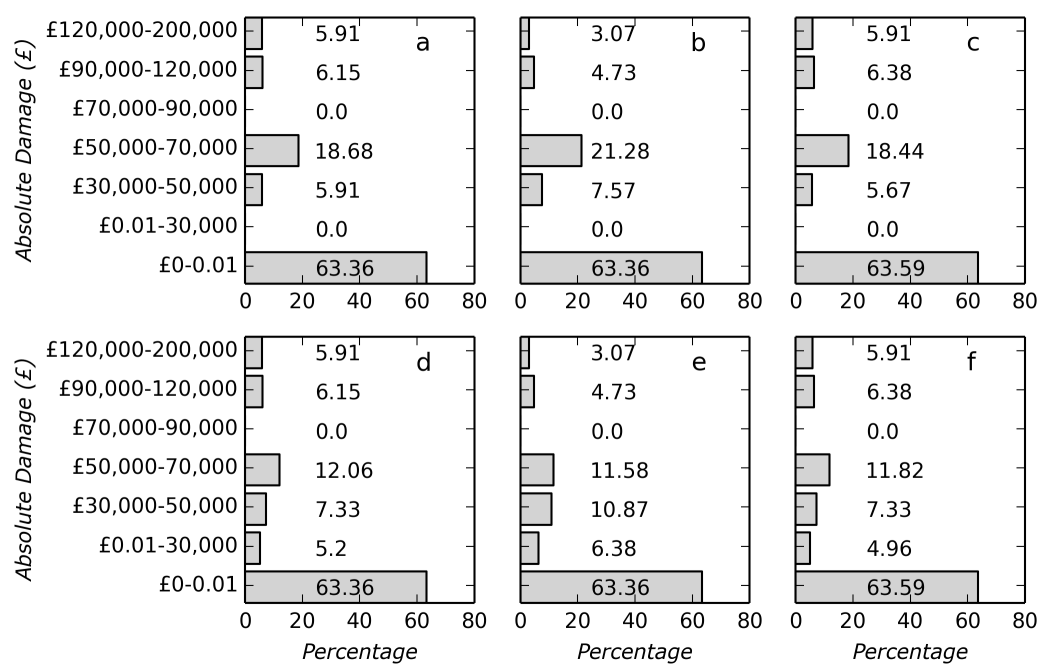

Figure 9: Absolute Commercial Damage values for the 1 in 100 year return period storm with a) No DRR measures, b) Extended sea wall c) Higher sea wall d) Display Boards e) Display Boards and Extended sea wall and f) Display Boards and Higher sea wall 
$97.6 \%$ of the people were not at risk to life, $2.3 \%$ at a low risk and $0.1 \%$ at a medium risk. The risk to life changed through the hazard influencing DRR measures, as the measures modified the maximum depth-velocity product in Wells. With an extended sea wall, risk to life was reduced compared to the no DRR case. $98.3 \%$ of the population was at no risk and $1.6 \%$ at a low risk. The higher sea wall had negligible influence on the risk to life. $97.5 \%$ of the population was at no risk, $2.3 \%$ at low and $0.1 \%$ at medium risk.

The saltmarsh was not influenced by the DRR measures due to its location seaward. For this 1 in 100 year storm, $98.4 \%$ of saltmarsh was undamaged, while $1.54 \%$ of the saltmarsh experienced changes within the normal seasonal variation of saltmarsh condition.

We observed similar effects of the DRR measures across all the storm scenarios of the BN. The higher sea wall showed a very similar distribution of damage to the no DRR measure option for all the storm scenarios, suggesting that the higher sea wall is not a suitable DRR measure at this location. The extended sea wall led to a slight reduction in damage to residential properties, a slight reduction in risk to life and a larger reduction in damage to commercial property. The display board DRR measure showed a general reduction in commercial and property damage for those properties with low inundation depth, however, at large flood depths this DRR measure had no effect.

\section{Discussion}

In this section we reflect on a number of aspects related to limitations and potential of the approach. A main advantage of the BN framework is that we can immediately predict what proportions of receptors experience hazards and ${ }_{610}$ consequences in distinct spatial zones of a site, when we impose evidence for the offshore boundary conditions of a storm scenario. This property is useful in operational forecasting and early warning system $3^{3}$. Many of them rely on ensemble forecasting to account for (some of the) uncertainties in initial conditions and model formulations of numerical weather predictions and regional hydrodynamics and wave models (e.g., see references in [77]). Hence, the boundary conditions that the $\mathrm{BN}$ should evaluate in the hot phase could be an ensemble instead of a point forecast. The BN could deal with such forecasts.

To explain how, we first consider the simple case of a single boundary condition variable influencing a single hazard variable. We recall that given a regular point estimate for the boundary condition, the BN predicts a distribution for the hazard. In the present application, the distribution can be interpreted as the proportions of receptors in the area that are affected. Thus, an ensemble of boundary conditions would link to an ensemble of hazard distributions. In the $\mathrm{BN}$, we can set the distribution of the boundary condition node so that it represents the ensemble members. The updated hazard distribution would then

${ }^{3}$ For technical details on integrating the BN into forecasting systems see Bogaard et al. [57]. They describe the integration into Delft-FEWS, a generic tool to set up such systems 
be an estimate of the ensemble mean hazard distribution. Additionally, we can obtain a worst-case and best-case hazard distribution, by conditioning on the lightest and the most severe boundary conditions, respectively.

In principle, the ensemble mean can be estimated for multiple boundary conditions as well, but we might introduce error, because they are modeled as independent in the BN. This model assumption is generally unproblematic for predictions based on fixed values of all boundary conditions. However, neglecting those dependencies can limit the BN's applicability for other purposes. In particular, this simplification can introduce error to the estimates of uncondi-

${ }_{635}$ tional hazard and consequence probabilities, as the BN evaluates the law of total probability. These probabilities would be necessary for risk assessments and to find the most economical suite of DRR measures [e.g., 78, 79]. The situation is similar for hazard and consequence probabilities that are computed for updated distributions of boundary conditions, for instance to represent an ensemble forecast. Finally, the assumption could also have effects on the diagnostic reasoning (i.e., in opposite arc direction) of the BN, because then the unconditional hazard and impact probabilities appear in the denominator of Bayes' theorem.

To expand the BN's potential for wider applications, the graph structure dictated by the framework should be adapted so that it can represent the multi${ }_{645}$ variate distribution of boundary conditions at case study sites more realistically. We also recommend, to investigate the influence of different discretizations on the dependence structure and, if necessary, to optimize it per site. Of course, a prerequisite for these extensions would be a multivariate statistical analysis of available boundary condition measurements or hindcast for the location of interest, for instance with copula-based approaches [13, 14.

Finally, a general limitation of the proposed BN approach is its reliance on synthetic data. While we need modeled data to gain insight into hazards and impacts of storms when field observations are lacking, the validity of the BN depends on the validity of the underlying data-generating models. At present, 655 we do not account for imperfections in those models, but future research should explore the sensitivity of $\mathrm{BN}$ predictions to errors or uncertainties in the data generation process.

\section{Conclusion}

We developed a BN approach to support decision making in coastal risk management. An important contribution is the learning algorithm for the BN, which integrates output from storm simulations with land use data, vulnerability relationships and DRR measures. The algorithm is programmed in $\mathrm{C}++$ and openly available at https://github.com/openearth/coastal-dss. We described the application to a small town in North Norfolk, UK, which is a risk hot spot ${ }_{65}$ during coastal storms.

The case study demonstrates how information flows through the BN and how it can predict onshore hazards and impacts, when provided with evidence of the offshore boundary conditions of a storm scenario. Because detailed data of severe storms including their hazards and impacts are almost never available, 

in the data-base is simulated with a $2 \mathrm{D}$ physics-based numerical model that covers the hot spot area. This way, the training data set captures the dependence between boundary conditions and various hazards, such as erosion and flood velocity, and reflects the complex influence of the local bathymetry. At

675 this stage, we take the precise locations of receptors into account. We include the dependence between hazards and impacts via vulnerability relationships, such as depth-damage-curves. Finally, we can also incorporate DRR measures. If they are structural, they are added through additional simulations with altered bathymetry. Otherwise, we assign them modified spatial distributions of receptors or vulnerability relationships.

The resulting $\mathrm{BN}$ forms a comprehensive and concise representation of risk propagation in a complex system of physical, ecological and human components. From a practical point of view, this integrative character, together with the capability to predict in real-time, makes the BN a helpful tool for decision makers. and can provide an objective basis for choosing DRR measures.

\section{Acknowledgments}

This work was supported by the European Community's 7th Framework Programme through the grant to RISC-KIT ("Resilience-increasing Strategies for Coasts - Toolkit"), contract no. 603458, and by contributions by the partner institutes. The authors would like to thank Nathaniel Plant for the fruitful discussions on this research. We would also like to thank the two anonymous reviewers for their valuable comments which helped to improve this manuscript.

\section{References}

[1] G. McGranahan, D. Balk, B. Anderson, The rising tide: assessing the risks of climate change and human settlements in low elevation coastal zones, Environment and Urbanization 19 (1) (2007) 17-37.

[2] M. E. Hubbard, N. Dodd, A 2D numerical model of wave run-up and overtopping, Coastal Engineering 47 (1) (2002) 1-26.

[3] D. Reeve, A. Soliman, P. Lin, Numerical study of combined overflow and wave overtopping over a smooth impermeable seawall, Coastal Engineering 55 (2) (2008) 155-166.

[4] J. Vrijling, Probabilistic design of water defense systems in The Netherlands, Reliability Engineering \& System Safety 74 (3) (2001) 337-344.

[5] G. Sills, N. Vroman, R. Wahl, N. Schwanz, Overview of New Orleans levee failures: lessons learned and their impact on national levee design and assessment, Journal of Geotechnical and Geoenvironmental Engineering 134 (5) (2008) 556-565. 
[6] P. Vellinga, Beach and dune erosion during storm surges, Coastal Engineering 6 (4) (1982) 361-387.

[7] P. J. Visser, Breach growth in sand-dikes, Ph.D. thesis, Delft University of Technology, Delft, 1998.

[8] S. N. Jonkman, M. Bočkarjova, M. Kok, P. Bernardini, Integrated hydrodynamic and economic modelling of flood damage in the Netherlands, Ecological Economics 66 (1) (2008) 77-90.

[9] S. N. Jonkman, B. Maaskant, E. Boyd, M. L. Levitan, Loss of life caused by the flooding of New Orleans after Hurricane Katrina: analysis of the relationship between flood characteristics and mortality, Risk Analysis 29 (5) (2009) 676-698.

[10] X. Bertin, N. Bruneau, J.-F. Breilh, A. B. Fortunato, M. Karpytchev, Importance of wave age and resonance in storm surges: the case Xynthia, Bay of Biscay, Ocean Modelling 42 (2012) 16-30.

[11] S. Hallegatte, C. Green, R. J. Nicholls, J. Corfee-Morlot, Future flood losses in major coastal cities, Nature Climate Change 3 (9) (2013) 802-806.

[12] R. Ernsteins, Participation and integration are key to coastal management, Coastal Management 52 (12) (2010) 636-645.

[13] C. De Michele, G. Salvadori, G. Passoni, R. Vezzoli, A multivariate model of sea storms using copulas, Coastal Engineering 54 (10) (2007) 734-751.

[14] T. Wahl, N. G. Plant, J. W. Long, Probabilistic assessment of erosion and flooding risk in the northern Gulf of Mexico, Journal of Geophysical Research: Oceans .

[15] I. Warren, H. Bach, MIKE 21: a modelling system for estuaries, coastal waters and seas, Environmental Software 7 (4) (1992) 229-240.

[16] J.-M. Hervouet, TELEMAC modelling system: an overview, Hydrological Processes 14 (13) (2000) 2209-2210.

[17] P. D. Bates, A. De Roo, A simple raster-based model for flood inundation simulation, Journal of Hydrology 236 (1) (2000) 54-77.

[18] D. Roelvink, A. Reniers, A. van Dongeren, J. van Thiel de Vries, R. McCall, J. Lescinski, Modelling storm impacts on beaches, dunes and barrier islands, Coastal Engineering 56 (11-12) (2009) 1133-1152.

[19] M. Ahern, R. S. Kovats, P. Wilkinson, R. Few, F. Matthies, Global health impacts of floods: epidemiologic evidence, Epidemiologic Reviews 27 (1) (2005) 36-46. 
[20] S. Hajat, K. Ebi, R. Kovats, B. Menne, S. Edwards, A. Haines, The human health consequences of flooding in Europe: a review, in: Extreme weather events and public health responses, Springer, 185-196, 2005.

[21] B. Merz, H. Kreibich, R. Schwarze, A. Thieken, Review article "Assessment of economic flood damage", Natural Hazards and Earth System Science 10 (8) (2010) 1697-1724.

[22] R. Brouwer, R. Van Ek, Integrated ecological, economic and social impact assessment of alternative flood control policies in the Netherlands, Ecological Economics 50 (1) (2004) 1-21.

[23] L. Poelhekke, W. S. Jäger, A. van Dongeren, T. A. Plomaritis, R. McCall, Ó. Ferreira, Predicting coastal hazards for sandy coasts with a Bayesian network, Coastal Engineering 118 (2016) 21-34.

[24] A. van Dongeren, P. Ciavola, G. Martinez, C. Viavattene, T. Bogaard, R. Higgins, R. McCall, Introduction to RISC-KIT: Resilience-increasing strategies for coasts, Coastal Engineering (this issue).

[25] M. W. Holdgate, A perspective of environmental pollution, Cambridge University Press Archive, 1980.

[26] P. Sayers, J. Hall, I. Meadowcroft, Towards risk-based flood hazard management in the UK, in: Proceedings of the Institution of Civil Engineers: Civil Engineering, vol. 150, 36-42, 2002.

[27] E. Evans, R. Ashley, J. Hall, E. Penning-Roswell, A. Saul, P. Sayers, C. Thorne, A. Watkinson, Foresight: Future flooding. Scientific summary: Volume I, Future risks and their drivers, Office of Science and Technology, London, 2004.

[28] S. Narayan, S. Hanson, R. Nicholls, D. Clarke, P. Willems, V. Ntegeka, J. Monbaliu, A holistic model for coastal flooding using system diagrams and the source-pathway-receptor (SPR) concept, Natural Hazards and Earth System Science 12 (5) (2012) 1431-1439.

[29] A. Burzel, D. R. Dassanayake, M. Naulin, A. Kortenhaus, H. Oumeraci, T. Wahl, C. Mudersbach, J. Jensen, G. Gönnert, K. Sossidi, et al., Integrated flood risk analysis for extreme storm surges (XtremRisK), in: Coastal Engineering Proceedings, 32, 2010.

[30] B. Gouldby, P. Samuels, Language of risk-project definitions. FLOODsite Project Report, T32-04-01, 2005.

[31] H. Oumeraci, A. Kortenhaus, A. Burzel, M. Naulin, D. Dassanayake, J. Jensen, T. Wahl, C. Mudersbach, G. Gönnert, B. Gerkensmeier, et al., XtremRisK - integrated flood risk analysis for extreme storm surges at open coasts and in estuaries: methodology, key results and lessons learned, Coastal Engineering Journal 57 (01). 
[32] S. Corbella, D. D. Stretch, Predicting coastal erosion trends using nonstationary statistics and process-based models, Coastal Engineering 70 (2012) 40-49.

[33] G. Salvadori, G. Tomasicchio, F. D'Alessandro, Practical guidelines for multivariate analysis and design in coastal and off-shore engineering, Coastal Engineering 88 (2014) 1-14.

[34] P. Boccotti, Wave mechanics for ocean engineering, Elsevier Oceanography Series, Elsevier Science, 2000.

[35] T. Wahl, C. Mudersbach, J. Jensen, Assessing the hydrodynamic boundary conditions for risk analyses in coastal areas: a multivariate statistical approach based on copula functions, Natural Hazards and Earth System Science 12 (2) (2012) 495-510.

[36] W. Jäger, O. Morales Nápoles, A Vine-Copula Model for Time Series of Significant Wave Heights and Mean Zero-Crossing Periods in the North Sea, ASCE-ASME Journal of Risk and Uncertainty in Engineering Systems, Part A: Civil Engineering (in press).

[37] P. D. Bates, R. J. Dawson, J. W. Hall, M. S. Horritt, R. J. Nicholls, J. Wicks, M. A. A. M. Hassan, Simplified two-dimensional numerical modelling of coastal flooding and example applications, Coastal Engineering 52 (9) (2005) 793-810.

[38] R. J. Dawson, M. E. Dickson, R. J. Nicholls, J. W. Hall, M. J. Walkden, P. K. Stansby, M. Mokrech, J. Richards, J. Zhou, J. Milligan, et al., Integrated analysis of risks of coastal flooding and cliff erosion under scenarios of long term change, Climatic Change 95 (1-2) (2009) 249-288.

[39] R. T. McCall, J. V. T. De Vries, N. Plant, A. Van Dongeren, J. Roelvink, D. Thompson, A. Reniers, Two-dimensional time dependent hurricane overwash and erosion modeling at Santa Rosa Island, Coastal Engineering 57 (7) (2010) 668-683.

[40] S. N. Jonkman, J. K. Vrijling, A. C. W. M. Vrouwenvelder, Methods for the estimation of loss of life due to floods: a literature review and a proposal for a new method, Natural Hazards 46 (3) (2008) 353-389.

[41] United Nations, UNISDR terminology on disaster risk reduction, 2009.

[42] N. Thurston, B. Finlinson, R. Breakspear, N. Williams, J. Shaw, J. Chatterton, Developing the evidence base for flood resistance and resilience. R\&D Technical Report. FD2607/TR1, 2008.

[43] L. Cumiskey, S. Priest, N. Valchev, S. Costas, J. Clarke, Pathways of interdependent Disaster Risk Reduction measures: Coastal impact assessment, Coastal Engineering (this issue). 
[44] L. Garrote, M. Molina, L. Mediero, Probabilistic forecasts using Bayesian networks calibrated with deterministic rainfall-runoff models, in: Extreme Hydrological Events: New Concepts for Security, Springer, 173-183, 2006.

[56] S. L. Lauritzen, D. J. Spiegelhalter, Local computations with probabilities on graphical structures and their application to expert systems, Journal of the Royal Statistical Society. Series B (Methodological) (1988) 157-224. 
[57] T. Bogaard, S. De Kleermaeker, W. S. Jäger, Development of generic tools for coastal forecasting and warning dissemination, Coastal Engineering (this issue).

[58] R. M. Cooke, Experts in uncertainty: opinion and subjective probability in science, Oxford University Press, 1991.

[59] C. Werner, T. Bedford, R. M. Cooke, A. M. Hanea, O. Morales-Nápoles, Expert judgement for dependence in probabilistic modelling: a systematic literature review and future research directions, European Journal of Operational Research 258 (3) (2016) 801-819.

[60] E. K. Christie, T. Spencer, D. Owen, A. McIvor, I. Möller, C. Viavattene, Regional coastal flood risk assessment for a tidally dominant, natural coastal setting: North Norfolk, southern North Sea, Coastal Engineering (this issue).

[61] P. J. Baxter, The east coast Big Flood, 31 January-1 February 1953: a summary of the human disaster, Philosophical Transactions of the Royal Society of London A: Mathematical, Physical and Engineering Sciences 363 (1831) (2005) 1293-1312.

[62] J. Steers, D. Stoddart, T. Bayliss-Smith, T. Spencer, P. Durbidge, The storm surge of 11 January 1978 on the east coast of England, Geographical Journal (1979) 192-205.

[63] T. Spencer, S. M. Brooks, B. R. Evans, J. A. Tempest, I. Möller, Southern North Sea storm surge event of 5 December 2013: water levels, waves and coastal impacts, Earth-Science Reviews 146 (2015) 120-145.

[64] N. Booij, L. Holthuijsen, R. Ris, The "SWAN" wave model for shallow water, in: Coastal Engineering Proceedings, 25, 668-676, 1996.

[65] N. Booij, I. Haagsma, L. Holthuijsen, A. Kieftenburg, R. Ris, A. van der Westhuysen, M. Zijlema, SWAN user manual, SWAN cycle III version 41.01, Delft University of Technology, 2014.

[66] M. I. Vousdoukas, E. Voukouvalas, A. Annunziato, A. Giardino, L. Feyen, Projections of extreme storm surge levels along Europe, Climate Dynamics 47 (9) (2016) 3171-3190.

[67] I. Möller, T. Spencer, J. French, D. Leggett, M. Dixon, Wave transformation over salt marshes: a field and numerical modelling study from North Norfolk, England, Estuarine, Coastal and Shelf Science 49 (3) (1999) 411426.

[68] I. Möller, M. Kudella, F. Rupprecht, T. Spencer, M. Paul, B. K. van Wesenbeeck, G. Wolters, K. Jensen, T. J. Bouma, M. Miranda-Lange, S. Schimmels, Wave attenuation over coastal salt marshes under storm surge conditions, Nature Geoscience 7 (10) (2014) 727-731. 
[69] I. Möller, Quantifying saltmarsh vegetation and its effect on wave height dissipation: Results from a UK East coast saltmarsh, Estuarine, Coastal and Shelf Science 69 (3) (2006) 337-351.

[70] T. Pullen, N. Allsop, T. Bruce, A. Kortenhaus, H. Schöter, J. Van der Meer, Wave overtopping of sea defences and related structure. Assessment Manual, 2007.

[71] E. Penning-Rowsell, S. Priest, D. Parker, J. Morris, S. Tunstall, C. Viavattene, J. Chatterton, D. Owen, Flood and coastal erosion risk management: a manual for economic appraisal, Routledge, 2014.

[72] S. J. Priest, T. Wilson, S. M. Tapsell, E. C. Penning-Rowsell, C. Viavattene, A. Fernandez-Bilbao, Building a model to estimate risk to life for European flood events. Project Report, 2007.

[73] C. D. Woodroffe, Coasts: form, process and evolution, Cambridge University Press, 2002.

[74] C. Viavattene, A. P. Micou, D. Owen, S. Priest, D. Parker, Coastal vulnerability indicator library. RISC-KIT Deliverable D2.2., 2015.

[75] Environment Agency, Public response to flood warnings. Technical Report, SC020116, 2007.

[76] JBA Consulting, Establishing the cost effectiveness of property flood protection. Technical Report, FD2657, 2012.

[77] L. Alfieri, P. Salamon, F. Pappenberger, F. Wetterhall, J. Thielen, Operational early warning systems for water-related hazards in Europe, Environmental Science \& Policy 21 (2012) 35-49.

[78] S. Jonkman, M. Kok, M. Van Ledden, J. Vrijling, Risk-based design of flood defence systems: a preliminary analysis of the optimal protection level for the New Orleans metropolitan area, Journal of Flood Risk Management 2 (3) (2009) 170-181.

[79] M. Woodward, Z. Kapelan, B. Gouldby, Adaptive flood risk management under climate change uncertainty using real options and optimization, Risk Analysis 34 (1) (2014) 75-92.

\section{Appendix A. Learning Algorithm for the Conditional Probability Ta- bles of Hazard Nodes}

Let $X_{h_{r}}$ denote a hazard node for receptor type $r$ with states $s_{h_{r}}=1, \ldots, S_{h_{r}}$. We denote DRR measures, boundary conditions and receptors analogously using the subscripts $m, b c$ and $r$ (cf. Table A.4).

Before learning the CPT, we introduce an experience matrix, $E$, of size $\mathbf{S}_{\mathbf{b c}} \times \mathbf{S}_{\mathbf{m} \in p a\left(h_{r}\right)} . \mathbf{S}_{\mathbf{b c}}$ is the vector of number of states of all boundary conditions 


Table A.4: Nomenclature for CPT learning
\begin{tabular}{|ll|}
\hline \multicolumn{2}{|l}{ Super - or Subscripts } \\
$n$ & simulation index \\
$b c$ & boundary condition index \\
$m$ & DRR measure index \\
$r$ & receptor type index \\
$h$ & hazard index \\
$p a$ & parent set \\
& \\
Variables \\
$X_{b c}$ & boundary condition $b c$ \\
$X_{m}$ & DRR measure $m$ \\
$X_{r}$ & receptor type $r$ \\
$X_{h_{r}}$ & hazard $h$ for receptor type $r$ \\
$E$ & experience matrix \\
& \\
Constants & number of states of $X_{b c}$ \\
$S_{b c}$ & number of states of $X_{m}$ \\
$S_{m}$ & number of states of $X_{r}$ \\
$S_{r}$ & number of states of $X_{h_{r}}$ \\
$S_{h_{r}}$ &
\end{tabular}

and $\mathbf{S}_{\mathbf{m} \in \text { pa }\left(h_{r}\right)}$ is the vector of the number of states of DRR measures in the parent set of $X_{h_{r}}$. Before learning, all entries are 0. For each simulation $n$ we set

$$
E^{(n)}\left[\mathbf{s}_{\mathbf{b c}}^{(n)}, \mathbf{s}_{\mathbf{m} \in p a\left(h_{r}\right)}^{(n)}\right]=E^{(n-1)}\left[\mathbf{s}_{\mathbf{b c}}^{(n)}, \mathbf{s}_{\mathbf{m} \in p a\left(h_{r}\right)}^{(n)}\right]+1 .
$$

Here, $\mathbf{s}_{\mathbf{b c}}^{(n)}$ and $\mathbf{s}_{\mathbf{m} \in p a\left(h_{r}\right)}^{(n)}$ denote the states of $\mathbf{X}_{\mathbf{b c}}^{(n)}$ and $\mathbf{X}_{\mathbf{m} \in p a\left(h_{r}\right)}^{(n)}$ in simulation $n$. Then, we compute, for each $s_{r}$ and $s_{h_{r}}$,

$$
\begin{gathered}
\operatorname{Pr}^{(n)}\left(X_{h_{r}}=s_{h_{r}} \mid \mathbf{X}_{\mathbf{b c}}=\mathbf{s}_{\mathbf{b c}}^{(n)}, \mathbf{X}_{\mathbf{m} \in p a\left(h_{r}\right)}^{(n)}=\mathbf{s}_{\mathbf{m} \in p a\left(h_{r}\right)}^{(n)}, X_{r}=s_{r}\right) \\
=\frac{\frac{m_{s_{r}, s_{h_{r}}}^{(n)}}{m_{r}}+p_{X_{h_{r}} \mid \mathbf{X}_{\mathbf{b c}}^{(n)}, \mathbf{X}_{\mathbf{m} \in p a\left(h_{r}\right)}^{(n)}, X_{r}}^{(n-1)} \cdot E^{(n-1)}\left[\mathbf{s}_{\mathbf{b c}}^{(n)}, \mathbf{s}_{\mathbf{m} \in p a\left(h_{r}\right)}^{(n)}\right]}{E^{(n)}\left[\mathbf{s}_{\mathbf{b c}}^{(n)}, \mathbf{s}_{\mathbf{m} \in p a\left(h_{r}\right)}^{(n)}\right]},
\end{gathered}
$$

where $m_{s_{r}, s_{h_{r}}}^{(n)}$ is the number of receptors of type $r$ in zone $s_{r}$ that experience hazard $X_{h_{r}}$ in state $s_{h_{r}}$ in simulation $n$. Further, we used $p_{X_{h_{r}} \mid \mathbf{X}_{\mathbf{b c}}^{(n)}, \mathbf{X}_{\mathbf{m} \in \text { pa }\left(h_{r}\right)}^{(n)}, X_{r}}^{(n-1)}$ to denote $\operatorname{Pr}^{(n-1)}\left(X_{h_{r}}=s_{h_{r}} \mid \mathbf{X}_{\mathbf{b c}}=\mathbf{s}_{\mathbf{b c}}^{(n)}, \mathbf{X}_{\mathbf{m} \in p a\left(h_{r}\right)}^{(n)}=\mathbf{s}_{\mathbf{m} \in p a\left(h_{r}\right)}^{(n)}, X_{r}=s_{r}\right)$. Thus, according to equation A.2, the CPT entries represent average proportions of receptors of type $r$ subjected to $s_{h_{r}}$ over all simulations with identical states for boundary conditions and DRR measures. 


\begin{tabular}{|c|c|}
\hline Special character & Meaning \\
\hline $\mathrm{p}$ & + \\
$\mathrm{m}$ & - \\
- & $\cdot$ \\
-- & to \\
\hline
\end{tabular}

Table B.5: Special characters used in state names in GeNIe

940

\section{Appendix B. BN for Wells-next-the-Sea in GeNIe}

As graphical user interface for the BNs we used GeNIe, which is available free of charge for academic research and teaching use from BayesFusion, LLC, http://www.bayesfusion.com/. Because the state names of the nodes in GeNIe must be strings with no spaces and no symbols, we resorted to special characters to represent positive or negative values, decimals and ranges (Table B.5).

Figure B.10 shows the quantified BNs with its prior distributions and Figure B.11 shows the quantified $\mathrm{BN}$ conditioned on the states corresponding to a 1 in 100 year return storm (water level $=4.41 \mathrm{~m}$; wave height $=2.17 \mathrm{~m}$ ). 


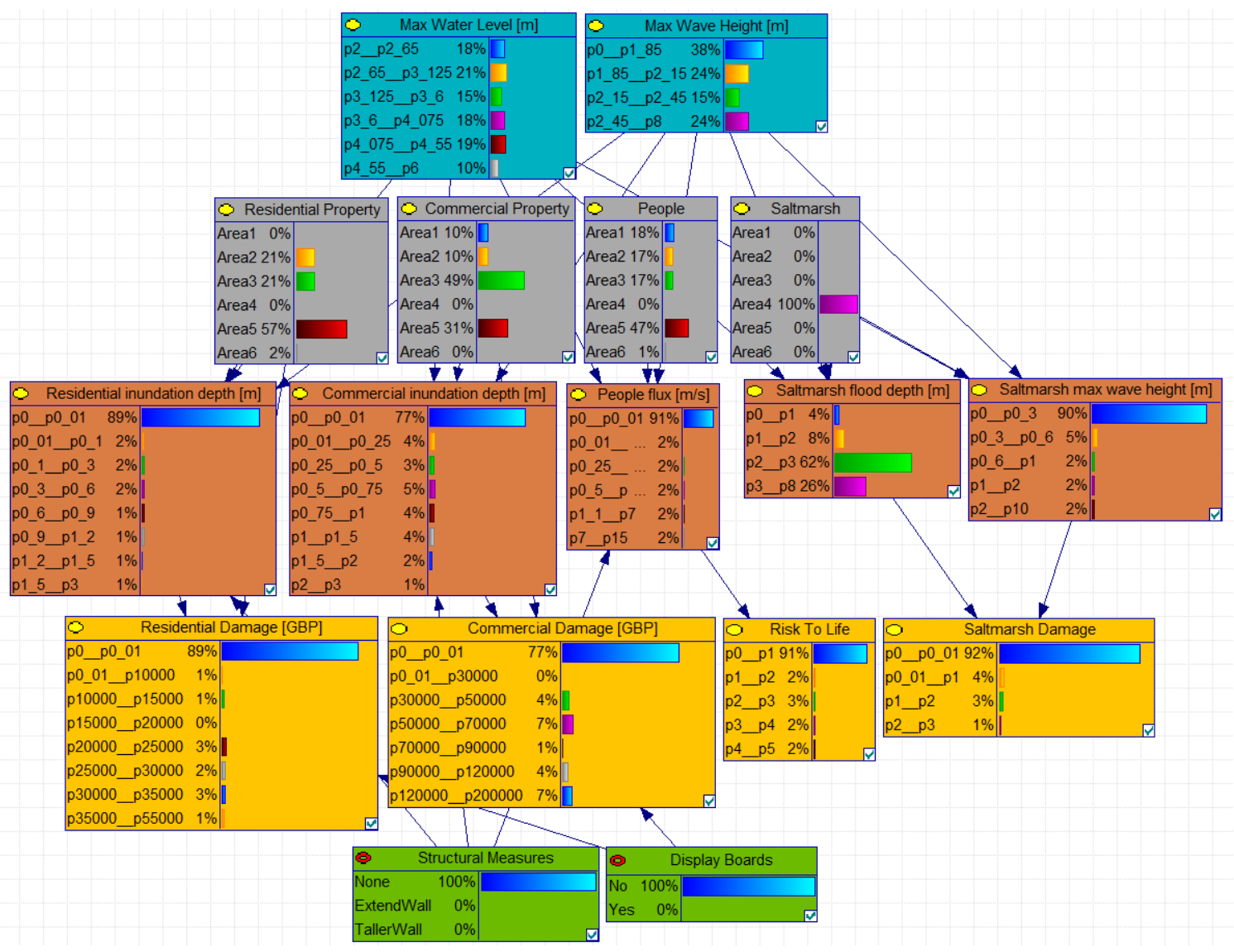

Figure B.10: Bayesian Network for Wells-next-the-Sea with prior distributions 


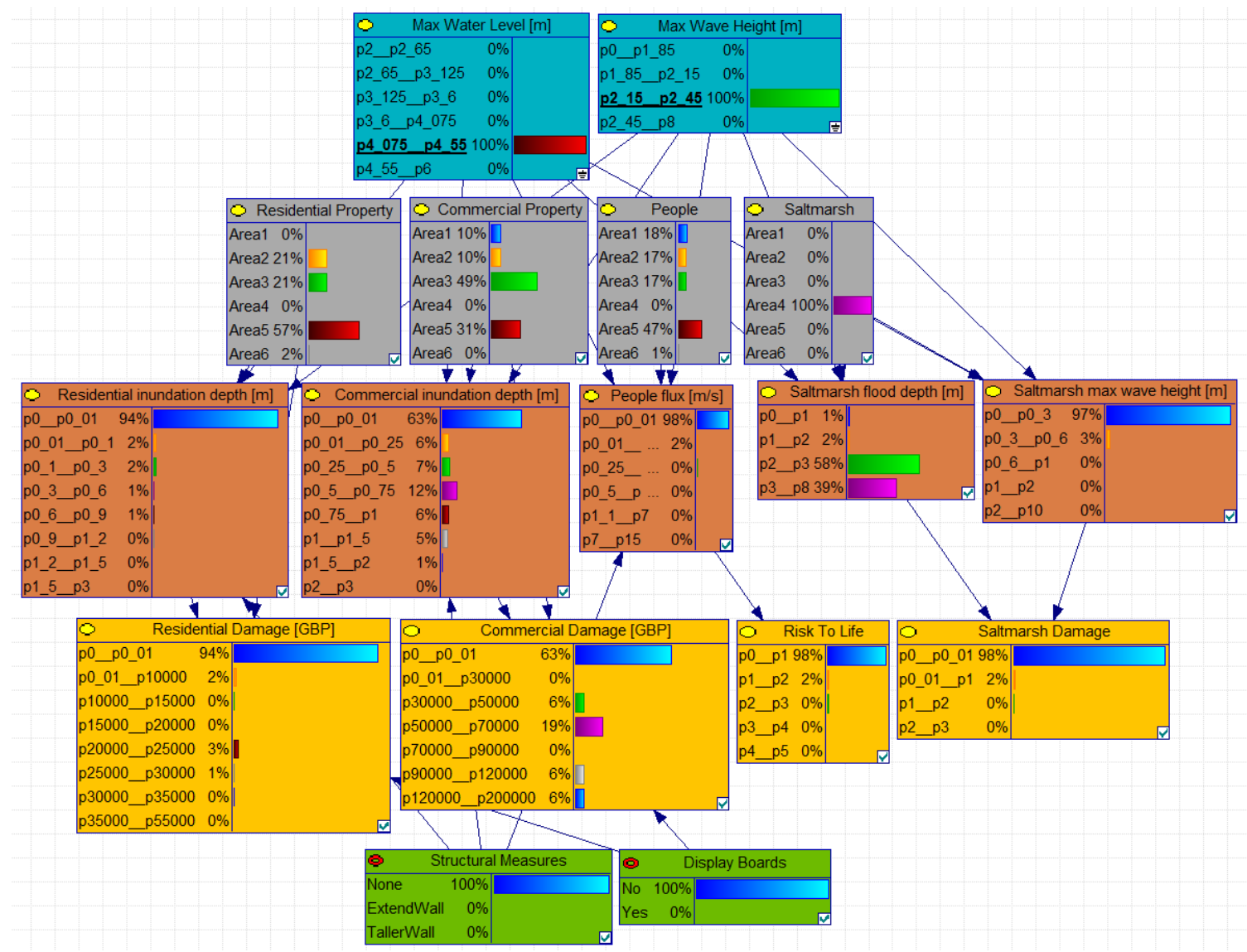

Figure B.11: Bayesian Network for Wells-next-the-Sea showing a 100 year return period event 